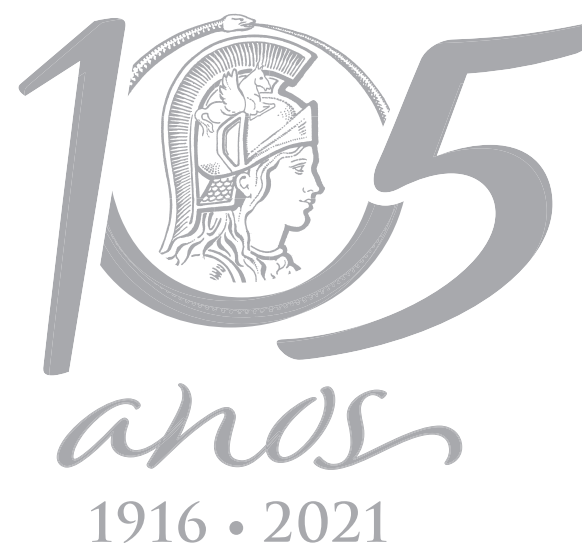

\title{
Morphological alterations in gastrointestinal organs of western-diet obese rats submitted to vertical sleeve gastrectomy or Roux-en-Y gastric bypass
}

\author{
ALANA G.C. GUIMARÃES, LUANA E.S. LOPES, ANGÉLICA N. CAPELASSI, ALLAN C.F. \\ ARAÚJO, SANDRA L. BALBO, HELENE N.H. BLANC, ISRAELLE N. FREITAS, JULIANA \\ N. SILVA, ROSANE A. RIBEIRO \& MARIA LÚCIA BONFLEUR
}

\begin{abstract}
To assess the effect of vertical sleeve gastrectomy (VSG) and Roux-en-Y gastric bypass (RYGB) on the esophageal and intestinal morphology of western diet (WD)-obese rats and to characterize the stomach histopathology of WD rats submitted to VSG. Male Wistar rats received WD from 2-4 months of age, to induce obesity, before randomly submitting them to pseudo (WD-SHAM), VSG (WD-VSG) or RYGB (WD-RYGB) surgeries. Gastrointestinal histomorphometry was performed at 3-months post-surgery. The upper esophagus of VSG and RYGB rats increased luminal area, while reductions in the keratin layer of the mucosa and the tunica muscularis were observed only in the RYGB animals. In the lower esophagus, both surgeries increased keratin layer thickness, but reduced the mucosal mucus content, while RYGB increased the thickness of the tunica mucosa and muscularis. The glandular region of the stomach of WD-VSG rats exhibited hypotrophy, epithelial erosion, fibrosis and moderate inflammatory infiltration. VSG and RYGB increased the villi height in the ileum, and the thickness of the tunica muscularis in the jejunum and ileum of WD rats; furthermore, RYGB augmented the ileal villi height. Thus both approaches induced histomorphological alterations in the esophagus and intestine and VSG damaged the gastric mucosa, even over the long-term.
\end{abstract}

Key words: Bariatric surgery, esophagus, obesity, small intestine, stomach.

\section{INTRODUCTION}

The obesity epidemic has reached alarming proportions worldwide, and is becoming the number one Public Health issue as, in addition to its direct organic impact, its multifactorial etiology predisposes individuals to several other chronic diseases (Chooi et al. 2019). From the age of 40 to 75 years, men and women that are mildly or severely obese exhibit reductions of 3-4 and 7-8 disease-free years, respectively, independently of socioeconomic status or favorable life-style factors (Nyberg et al. 2018). In addition, increased adiposity augments the risk of all forms of mortality, with higher degrees of obesity being associated with greater reductions in life expectancy (Aune et al. 2016, Bhaskaran et al. 2018).

Bariatric operations are reported to be the most effective treatment for morbid obesity or obese subjects with several comorbidities. Vertical sleeve gastrectomy (VSG) and Roux-en-Y gastric bypass (RYGB) are the most performed bariatric techniques. While VSG is a restrictive procedure that reduces the size of the stomach by $80 \%$, RYGB combines a restrictive procedure 
(reducing the gastric volume to around 5\%) with a malabsorptive mechanism, by connecting the gastric pouch to the mid-jejunum (Angrisani et al. 2018). It is now known that these bariatric operations lead to weight loss and metabolic improvements through various mechanisms that are not only dependent upon the restriction and/or malabsorption of the food ingested (Pucci \& Batterham 2019).

The gastrointestinal morphophysiology may be significantly affected by obesity. Obesity increases the risk of hiatus hernia, gastroesophageal reflux, Barret's esophagus, esophagitis, gastritis, microbiota dysbiosis, disruptions in the esophagus, gastric and gut motility, and the occurrence of various types of cancers in the gastrointestinal tract (Feakins 2016, Fayfman et al. 2019, Braghetto \& Korn 2019). Thus, it is hypothesized that, in addition to benefits on body mass and metabolism, bariatric surgeries may reduce or recuperate the above-mentioned gastrointestinal impairments in obese individuals. However, studies present conflicting results with regard to most of the bariatric techniques performed, as VSG and RYGB have been shown to improve, rather than damage, gastrointestinal morphofunction in obesity (Perry et al. 2004, Merrouche et al. 2007, Cassao et al. 2013, Del Genio et al. 2014, Altieri et al. 2015, Braghetto \& Korn 2019), highlighting the necessity for further investigations regarding the morphophysiology of the gastrointestinal tract following these surgeries.

Experimentally, the best model of obesity is obtained by the ingestion of a Western diet (WD) by lab rodents, as this diet replicates the hypercaloric diets and soft drinks that humans ingest. As a consequence, WD-fed rodents develop several obesity metabolic disruptions and gastrointestinal dysfunctions, such as enlargements of the stomach and gut, disruptions in gut morphology, motility, nutrient absorption and microbiota (Dameto et al. 1991, Planas et al. 1992, Becerril et al. 2005, Almeida et al. 2014, Balbo et al. 2016, Del Bas et al. 2018). Thus, we characterized and compared the esophageal and intestinal morphology of WD-obese rats that underwent the VSG and RYGB surgeries. In addition, as the effects of VSG on stomach morphology have only been described in rodents submitted to normolipidic or hyperlipidic diets (Martin et al. 2012, Arapis et al. 2015), we also performed a histopathological analysis of the stomach of WD rats submitted to VSG.

\section{MATERIALS AND METHODS}

\section{Induction of obesity, and SHAM and bariatric operations}

Sixty day-old Wistar rats were maintained in collective cages, on a 12h light/dark cycle (lights on 07:00-19:00 h) and controlled temperature $\left(22 \pm 1^{\circ} \mathrm{C}\right)$, and received a Western diet (WD) to induce obesity (diet composition described in Balbo et al. 2016). After two months of WD intake, all rats received a liquefied WD for 5 days. For SHAM or bariatric operations, all WD rats were food deprived for $12 \mathrm{~h}$, and were randomly submitted to SHAM (WD-SHAM), VSG (WD-VSG) or RYGB (WD-RYGB) procedures. All rats were weighed first and then anesthetized with $1 \%$ isoflurane (BioChimico, Itatiaia, BRA), under oxygen ventilation at $1 \mathrm{~L} / \mathrm{min}$ using nasotracheal intubation. Animals then received $50 \mathrm{mg} / \mathrm{kg}$ of body weight (BW) sodium dipyrone (Teuto, Anápolis, BRA) for analgesia, and a single intramuscular injection of $50 \mathrm{mg} / \mathrm{kg}$ BW ceftriaxone (Teuto, Anápolis, GO, BRA) as antibiotic prophylaxis.

As previously described by Silva-Morita et al. 2018, for SHAM and bariatric operations, a 4 $\mathrm{cm}$ incision was made at the epigastric midline of the abdomen in all WD rats. Subsequently, 
in the WD-SHAM group, the stomach and small intestine were carefully handled. For VSG, a section of the stomach was made using a pair of scissors, from the angle of His to $3 \mathrm{~mm}$ proximal to the duodenum, with resection of $80 \%$ of the greater curvature of the stomach. Subsequently, the sectioned stomach was sutured using polypropylene 7-0 yarn. For RYGB, the left gastric vessels and their first branches in the cardia of rats were connected or cauterized and then separated from the esophagus. The stomach was cut, creating a gastric pouch of approximately $<5 \%$. The excluded stomach was sutured with 7-0 polypropylene yarn with continuous stitching. The jejunum was then transected $10 \mathrm{~cm}$ distal to the ligament of Treitz and anastomosed, in this region, to the small gastric pouch. The proximal limb of the jejunum was reconnected downwards at a distance of 15 $\mathrm{cm}$ from the gastrojejunostomy using a side-toside jejunojejunostomy. At the end of SHAM, VSG and RYGB surgeries, the abdominal walls of all rats were sutured by planes of the muscles and skins using 4-0 polypropylene yarn.

After the surgeries, all rats received $10 \mathrm{~mL}$ $0.9 \%$ saline solution subcutaneously, to prevent dehydration. During the $72 \mathrm{~h}$ post operation, all rats received just water ad libitum. Afterwards, they were fed on a liquefied WD for 7 days and then returned to their solid WD for more 3 months (Figure 1 shows a timeline representation of the experimental obesity induction and the SHAM

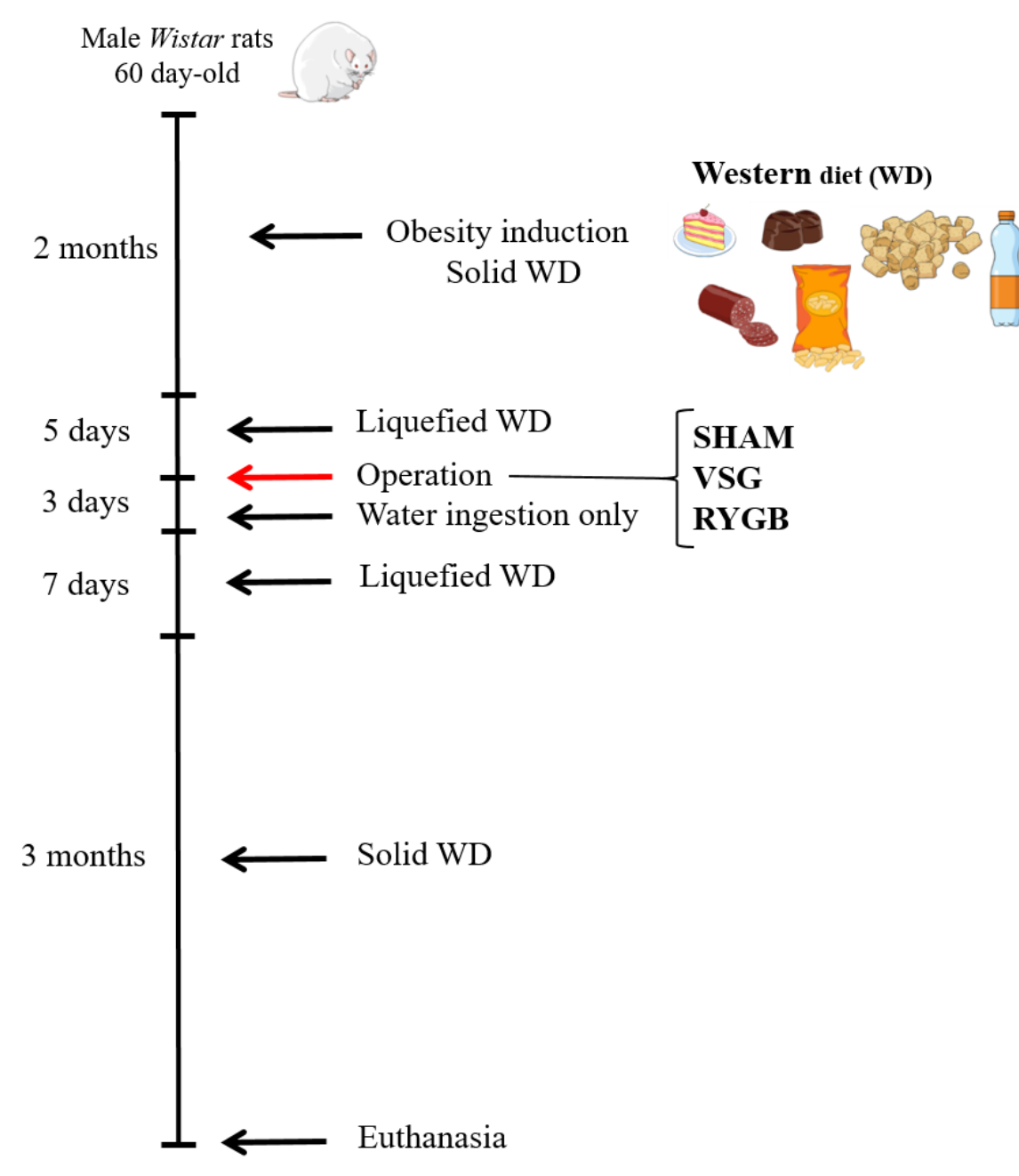

Figure 1. Timeline representation of obesity induction and SHAM or bariatric operation of experimental groups. Obesity was induced by the ingestion for 2 months of a western diet (WD) in male Wistar rats. Subsequently, WD rats were submitted to a liquefied WD for 5 days and were randomly submitted to SHAM (WD-SHAM), VSG (WD-VSG) or RYGB (WDRYGB) operations. During the 3 days post operation, all rats received just water ad libitum. Afterwards, they were fed on a liquefied WD for 7 days and then returned to their solid WD for 3 months. 
or bariatric operations in all rat groups). All experimental procedures performed in Wistar rats in this study were approved by the Ethics Committee on Experimentation and Animal Use of the State University of Western Paraná (06/09/2015).

\section{Body weight (BW) and adiposity evaluation}

All WD rats were weighed on the day of SHAM, VSG or RYGB operations, and thereafter, once a month. At 3 months after the operations, WD rats were weighed to obtain their final BWs, and were then euthanized by decapitation before performing laparotomy to remove and weigh the periepididymal and retroperitoneal fat pads. The monthly or total BW gains after SHAM or bariatric operations were obtained by subtraction of BW registered on the day of the operation from the final BW.

\section{Histopathology and morphology of the esophagus, stomach and small intestine}

After euthanasia, the esophagus was excised and cut in the middle, obtaining 2 regions; the upper esophagus, which comprises its upper regions until its half-way part; and the lower esophagus, that comprises the rest of this tube until close to its junction with the stomach. Fragments of $2 \mathrm{~cm}$ of the duodenum, jejunum, and ileum were also excised from all rat groups. The whole stomach was collected from WDSHAM and WD-VSG rats. Tissues were fixed in $4 \%$ paraformaldehyde for $48 \mathrm{~h}$ and samples were then dehydrated with ethanol, cleared with xylene and embedded in paraffin. Semiserial ( $5 \mu \mathrm{m}$-thick) sections were obtained for tissues and submitted to hematoxylin and eosin (HE) staining. In addition, sections of the esophagus and stomach were also stained with periodic acid Schiff (PAS) or Sirius red dye to analyze the amount of carbohydrate (mucin) or collagen, respectively, in the tunica mucosa.
For morphometric analysis, the tissues were photographed using a digital camera (Olympus DP71, Olympus Optical, São Paulo, SP, BRA) coupled to an optical microscope (Olympus BX51, Olympus Optical, São Paulo, SP, BRA). Three sections from each tissue per rat were photographed.

Morphometric measurements of the thickness of the layers or tunicas of all tissues, as well as the height of villi and depths of crypts, were measured in images from sections stained with $\mathrm{HE}$, using the straight tool of the Image J Software (https://imagej.nih.gov/ij/ download.html); pixel intensities were converted to micrometers $(\mu \mathrm{m})$ by the calibration of this software with a slide containing a $\mu \mathrm{m}$ scale. The percentage positive areas stained to PAS or Sirius red were also obtained with the aid of Image J Software. The specific threshold for the purple or red colors, which represent total carbohydrates or collagen fiber staining, respectively, were first determined and a square was applied over these colors and recorded using the Software, which also converted total pixel numbers/intensities to $\mu \mathrm{m}$. In addition, the histopathology of stomach sections of WDSHAM and WD-VSG rats were blind examined by an expert pathologist for analysis of mucosal edema, erosion of the mucosa, hemorrhage, hyperemia, atrophy, and fibrosis, presence of inflammatory infiltrate and cellular atypia.

\section{Statistical analyses}

Results are expressed as means \pm standard error of the mean (SEM) of the numbers of rats indicated in the figure legends. Data were first analyzed using the Komorogov-Smirnov test and then submitted to parametric (Student $t$ test or one-way ANOVA followed by NewmanKeuls post-test) or non-parametric (Mann Whitney U-test or Kruskal-Wallis followed by Dunns multiple comparison post-test) 
comparison using GraphPad Prism version 5.00 (GraphPad Software, San Diego, USA). The level of significance was set at $P<0.05$.

\section{RESULTS}

\section{Obesity parameters evaluated in WD rats} submitted to bariatric or SHAM operations

The BW in the day of surgery was similar among the groups of WD rats that were randomly submitted to SHAM operations (Fig. 2a). At one month after these operations, neither the WDVSG nor the WD-RYGB rats presented BW gain during the post-surgery period (WD-VSG - $4.0 \pm$ 12.9; WD-RYGB $0.0 \pm 10.6$ g BW gain), whilst WDSHAM rats exhibited a progression in BW gain $(60.8 \pm 5.0$ g; $P<0.05)$. Subsequently, WD-VSG rats started to display an increase in BW, resulting in a greater BW gain during the last 2 months of the experimental period $(83.0 \pm 6.8 \mathrm{~g})$, than that observed for WD-RYGB rats $(38.0 \pm 3.9 \mathrm{~g}$; $\mathrm{P}<0.05)$.

At 3 months after the operations, WD rats that had undergone RYGB exhibited reductions (a)

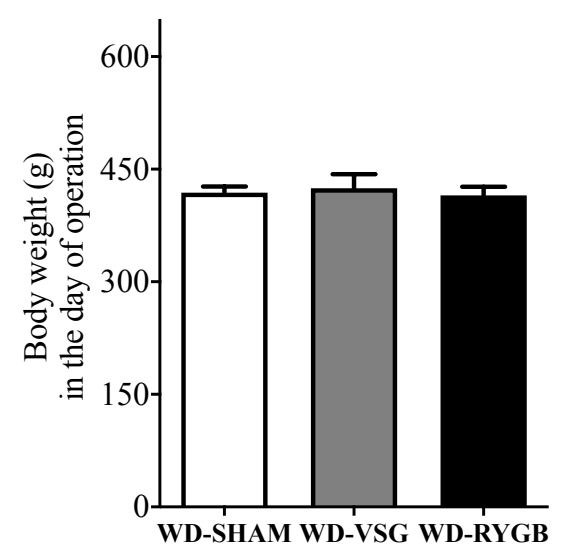

(d) (b)

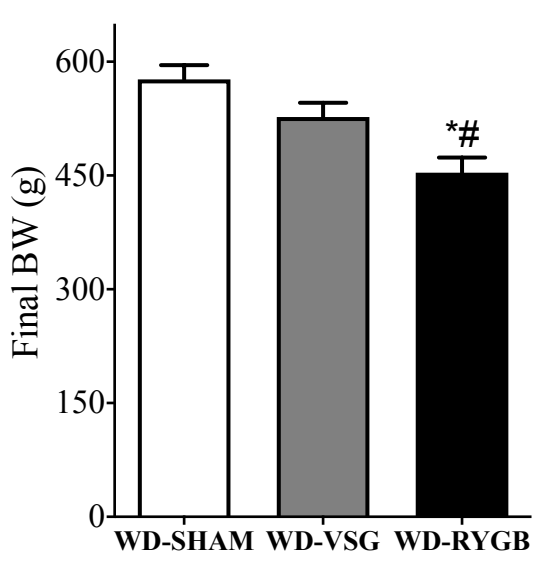

(c)

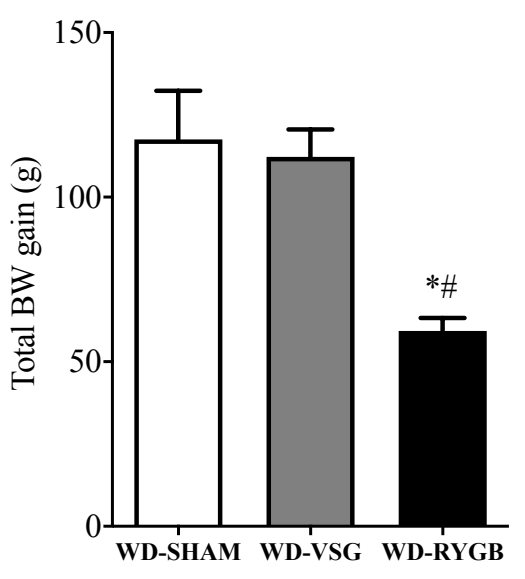

(e)
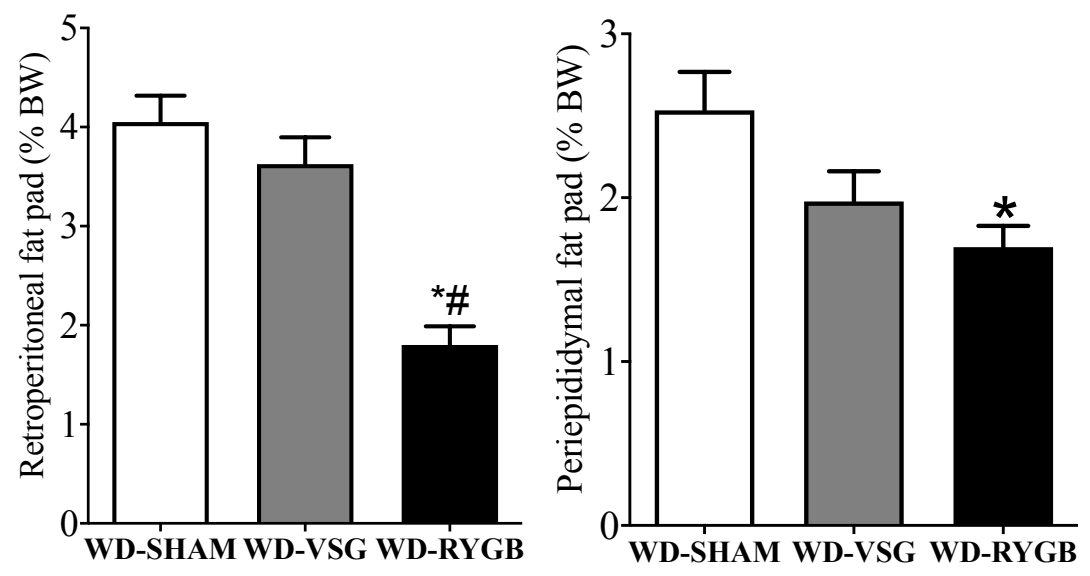

Figure 2. Means \pm SEM of BW in the day of operation (a), final BW (b), total BW gain (c), and weights of retroperitoneal (d) and periepididymal (e) fat pads of WD-SHAM ( $n=8)$, WD-RYGB $(n=9)$ and WD-VSG ( $n=6)$ rats. *different from WD-SHAM; \#different from the other type of bariatric operation (Kruskal-Wallis followed by Dunns post test, $\mathrm{P}<0.05)$. 
of $21 \%$ and $49.5 \%$ in final BW and total BW gain, than that observed for WD-SHAM rats ( $P$ $<0.01$ and $P<0.05$, respectively; Fig. $2 b$ and $2 c$ ). Additionally, only the RYGB operation reduced the retroperitoneal and periepididymal fat depositions in WD-RYGB rats, when compared with WD-SHAM rats $(P<0.0001$ and $P<0.05$, respectively; Fig. $2 \mathrm{~d}$ and $2 \mathrm{e}$ ). In contrast, final BW, total BW gain, and the weights of retroperitoneal and periepididymal fat pads in WD-VSG rats, did not differ from WD-SHAM (Fig. 2b-2e). Notably, WD-RYGB rats exhibited reductions in final BW, total BW gain and retroperitoneal fat pad weight, respectively, when compared with WD-VSG rats $(P<0.0001, P<0.05$ and $P<0.05$, respectively; Fig. 2b-2d).

\section{Esophagus morphology of WD rats submitted to bariatric or SHAM operations}

Figure 3 shows the morphological analyses of the upper region of the esophagus of WD rats submitted to bariatric or SHAM operations. WDRYGB rats displayed a reduction in the keratin layer of the mucosa tunica, but an increase in epithelium thickness, when compared with the WD-SHAM and WD-VSG groups ( $<$ 0.0001; Fig. 3a and 3f). Furthermore, RYGB diminished the thickness of tunica muscularis in the WDRYGB rats $(P<0.01$; Fig. 3i). In contrast, the VSG operation did not change these morphological parameters in WD-VSG rats, in comparison with WD-SHAM (Fig. 3a and 3f), however, it decreased the PAS-positive percentage area in the tunica mucosa $(P<0.01$; Fig. 3g). Both bariatric operations lowered the Sirius red positivity and, therefore, collagen deposition in the epithelium of the mucosa of WD-VSG and WD-RYGB rats, when compared with WD-SHAM rats $(P<0.0001$; Fig. 3h). In addition, both bariatric operations augmented the esophageal lumen in WD rats, compared to WD-SHAM rats $(P<0.05$; Fig. $3 e$ and 3j), without altering the total wall circumference of this esophageal region (Fig. 3j).

In the lower esophagus, both the VSG and RYGB operations increased the thickness of the keratin layer in the tunica mucosa of WD rats, when compared with WD-SHAM rats $(P<0.01$; Fig. $4 \mathrm{a}$ and $4 \mathrm{f}$ ). However, only the RYGB surgery increased the thickness of the epithelial layer and of the tunica mucosa of WD-RYGB rats, when compared to WD-SHAM ( $P<0.0001$; Fig. $4 \mathrm{a}$ and 4f). WD-VSG and WD-RYGB rats exhibited lower PAS staining in the epithelium of the tunica mucosa ( $P<0.0001 ;$ Fig. 4b and 4g). Conversely, only the VSG operation decreased the collagen content in the mucosal epithelium in WD-VSG, when compared with WD-SHAM rats $(P<0.01$; Fig. $4 \mathrm{C}$ and $4 \mathrm{~h}$ ). The RYGB surgery increased the thickness of the tunica muscularis in the WD-RYGB rats, when compared with the WDSHAM group ( $P$ < 0.0001; Fig. $4 \mathrm{~d}$ and $4 \mathrm{i})$. Bariatric operations increased the lumen area in the WDVSG and WD-RYGB rats $(P<0.05$ and $P<0.0001$, respectively; Fig. $4 \mathrm{e}$ and $4 \mathrm{j}$ ); but only the RYGB procedure increased the wall circumference area of the lower esophagus ( $P<0.0001$; Fig. 4j).

\section{Stomach histopathology of WD rats submitted to VSG or SHAM operations}

Figure 5 shows the histomorphometry analyzes of nonglandular and glandular regions of the stomachs of WD-VSG and WD-SHAM rats. In the nonglandular portion, no alterations in the thickness of the mucosal layers or tunica mucosa were observed among WD-VSG and WD-SHAM rats (Fig. $5 \mathrm{a}$ and 5e). However, the percentage area that stained for collagen was significantly lower in the WD-VSG, when compared with WD-SHAM rats $(P<0.0001$; Fig. $5 \mathrm{C}$ and $5 f$ ). Furthermore, the percentage PAS positive area in the mucosal tunica (Fig. 5b and 5f) and the thickness of the tunica muscularis 
(a)

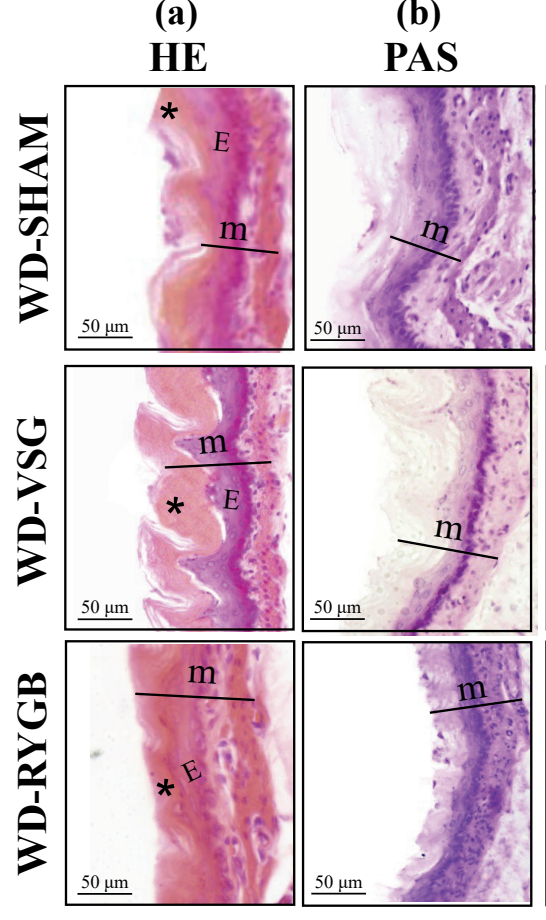

(f)

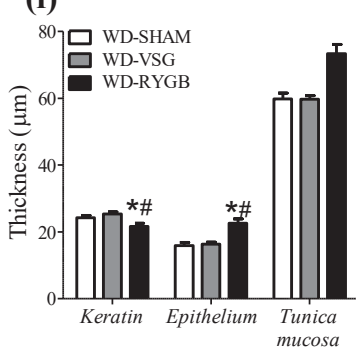

(c)
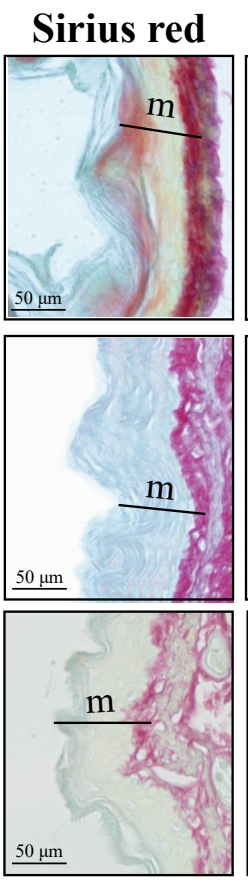

(d)

HE
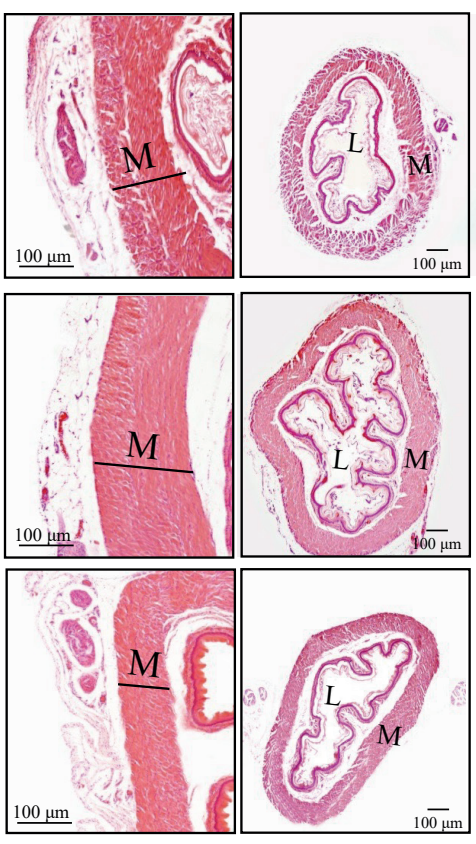

(e)

HE 


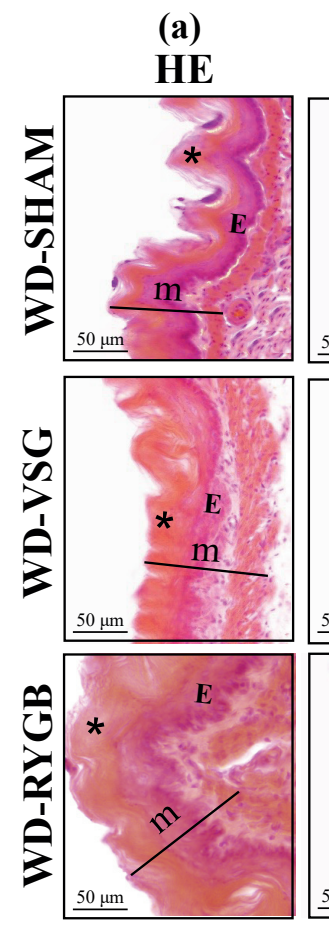

(b)
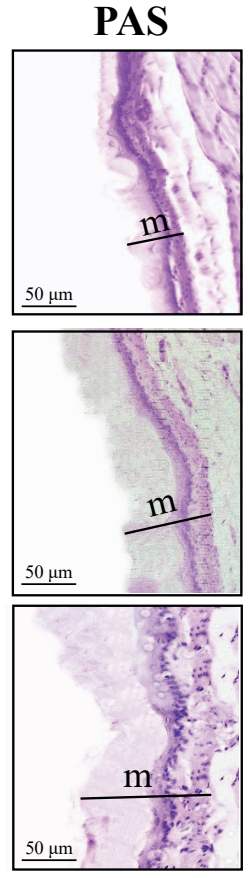

(c)
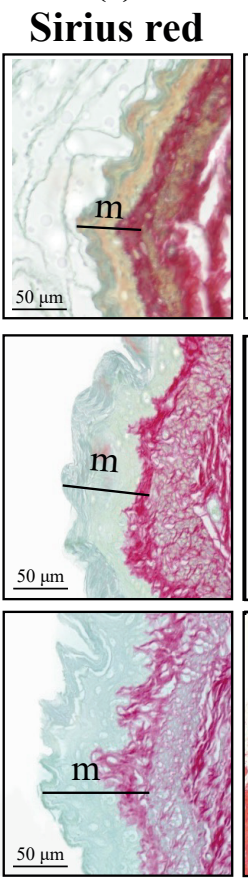

(d)

HE
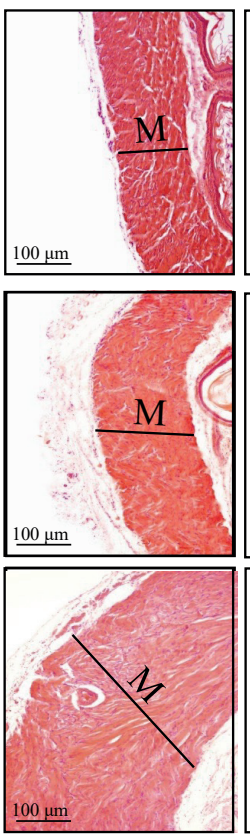

(e)

HE
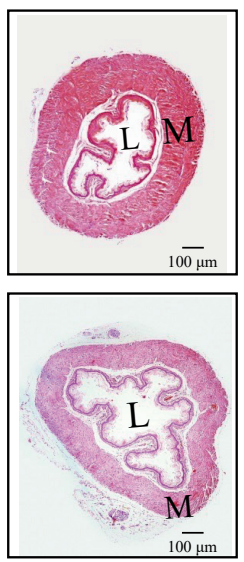

(f)

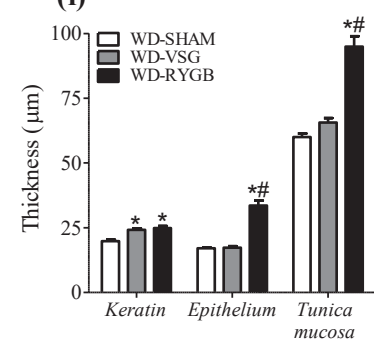

(g)

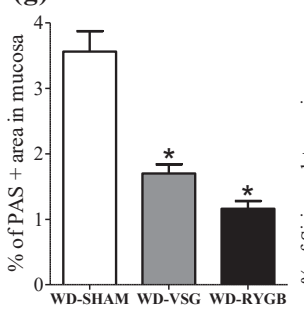

(h)

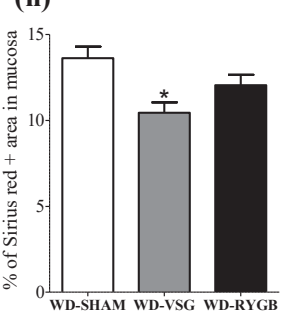

(i)

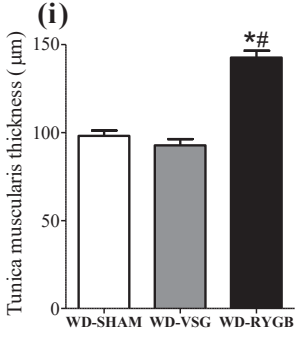

(j)

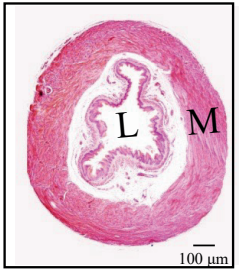

Figure 4. Representative images of 5- $\mu$ m-thick sections of the lower esophagus of WD-SHAM, WD-VSG and WDRYGB rats, at 3 months after operations. Sections were stained with $\mathrm{HE}\left(\mathrm{a}, \mathrm{d}\right.$ and $\mathrm{e}$; ${ }^{*}=$ keratin layer; $\mathrm{E}=$ epithelium layer; $m$ = tunica mucosa; $M=$ tunica muscularis; $L=$ lumen), or periodic acid Schiff (PAS; $B ; m=$ tunica mucosa) or sirius red ( $c ; m=$ tunica mucosa). Scale bars $=50$ or $100 \mu \mathrm{m}$. Means \pm SEM of the keratin layer, epithelium and tunica mucosa $(\mathrm{f})$, percentage of PAS ( $\mathrm{g}$ ) or Sirius red $(\mathrm{h})$ positive areas in the tunica mucosa, thickness of tunica muscularis (i), and lumen and wall circumference area ( $j$ ) of the lower esophagus; of total tunica mucosa (d), tunica muscularis (e) and tunica adventitia (f) thickness in the lower esophagus of WD-SHAM $(n=5)$, WD-VSG $(n=5)$ and WD-RYGB $(n=5)$ rats. *different from WD-SHAM; \#different from the other type of bariatric operation (KruskalWallis followed by Dunns post test, $\mathrm{P}<0.05)$.

without changes in total tunica mucosa thickness ( $P<0.0$ Fig. 5a and 5h). VSG enhanced collagen deposition in the epithelium of the mucosa in WD-VSG, when compared with the WD-SHAM group ( $P<0.0005$; Fig. $5 C$ and $5 i)$. Furthermore, the stomach of the WD-VSG rats demonstrated an increase in the thickness of the tunica muscularis, compared to that observed for WDSHAM rats $(P<0.01$; Fig. $5 d$ and $5 j)$.

\section{Morphology of the small intestine of WD rats submitted to VSG or SHAM operations}

Figure 7 shows representative histological sections and histomorphometric analysis of the small intestine of WD rats at 3 months 
Figure $5 \quad$ (a)
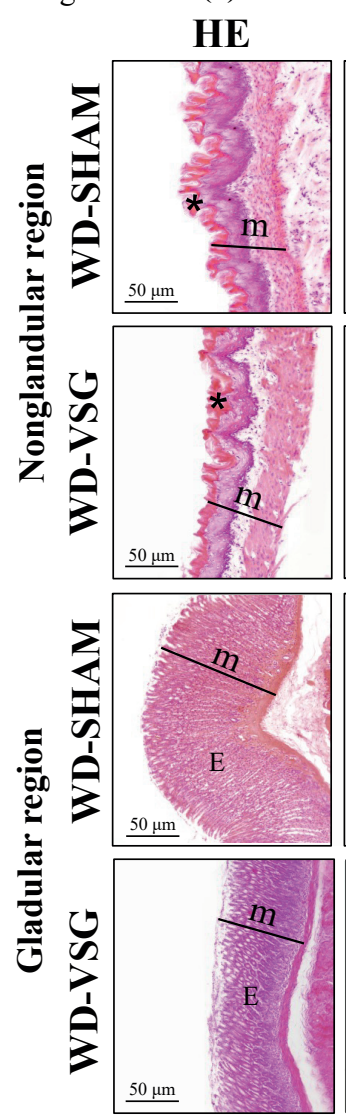

(b)
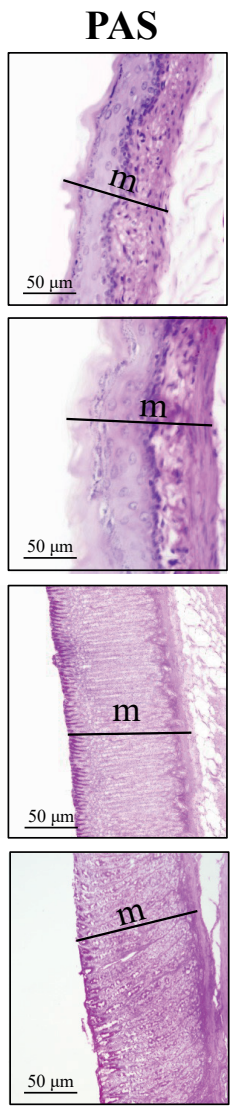

(c)
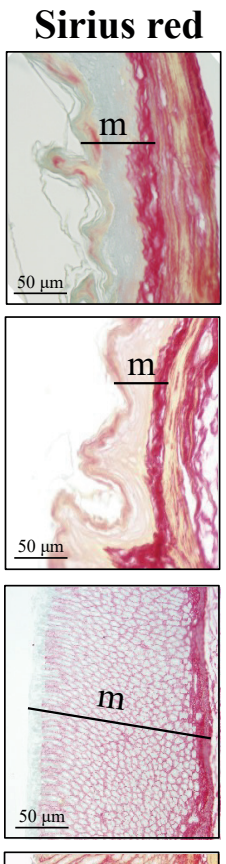

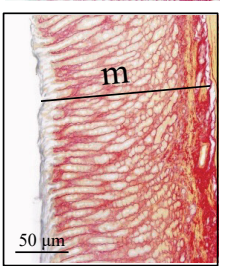

(d)

HE
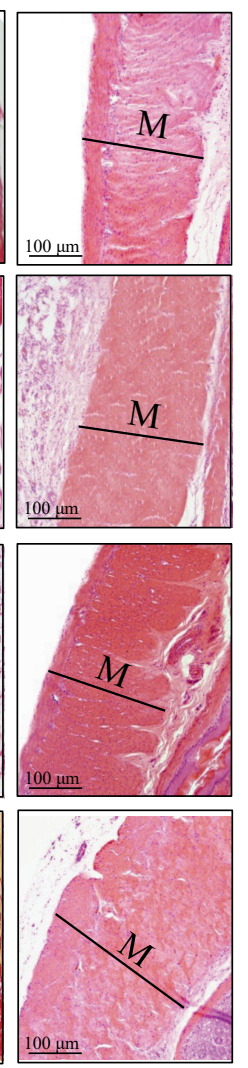

(e)

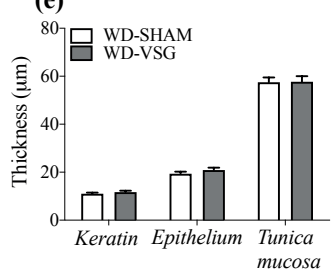

(f)

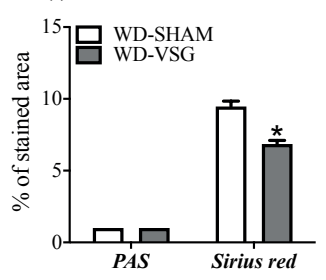

(g)

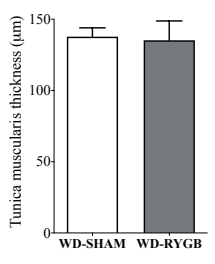

(h)
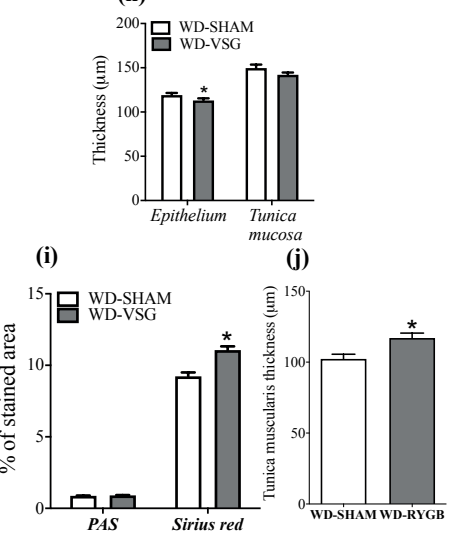

Figure 5. Representative images of 5- $\mu \mathrm{m}$-thick sections of the non-glandular and glandular regions of the stomachs of WD-SHAM and WD-VSG rats, at 3 months after operations. Sections were stained with HE (a and d; * $=$ keratin layer; $\mathrm{E}=$ epithelium layer; $\mathrm{m}=$ tunica mucosa; $\mathrm{M}=$ tunica muscularis), or periodic acid Schiff (PAS; $b ; \mathrm{m}$ $=$ tunica mucosa) or sirius red $(c ; m=$ tunica mucosa). Scale bars $=50$ or $100 \mu \mathrm{m}$. Means \pm SEM of the thickness of keratin and epithelium layers, and tunica mucosa (e and $h$ ), percentage of PAS or Sirius red ( $f$ and $i)$ positive areas in tunica mucosa, and the thickness of the tunica muscularis ( $g$ and $j)$, of nonglandular and glandular regions, respectively, in the stomach of WD-SHAM $(n=5)$ and WD-VSG $(n=5)$ rats. *different from WD-SHAM (Mann Whitney U-test, $\mathrm{P}<0.05)$.

after the SHAM or bariatric operations. Despite demonstrating tendencies toward decreases in some parameters, no significant differences in duodenal morphology were observed among the WD-VSG, WD-RYGB and WD-SHAM rats (Fig. 7a-7d). Both bariatric operations increased the villi height in the jejunum (Fig. 7e and 7f), and the thickness of the tunica muscularis in the jejunum and ileum of WD-VSG and WD-RYGB rats (Fig. 7e, 7h, 7i and 7l), when compared with WDSHAM rats $(P<0.05)$. WD-RYGB rats also exhibited an augmented ileal villi height, compared to that observed in the gut of WD-SHAM rats ( $P$ $<0.01$; Fig. 7i and 7j). No modifications in the crypt depth were observed along the regions of the small intestine in WD rats submitted to bariatric operations (Fig. 7d, 7g and 7k). Table I summarized the morphological modifications per gastrointestinal organ of WD-SGV or WDRYGB rats, when compared to WD-SHAM. 

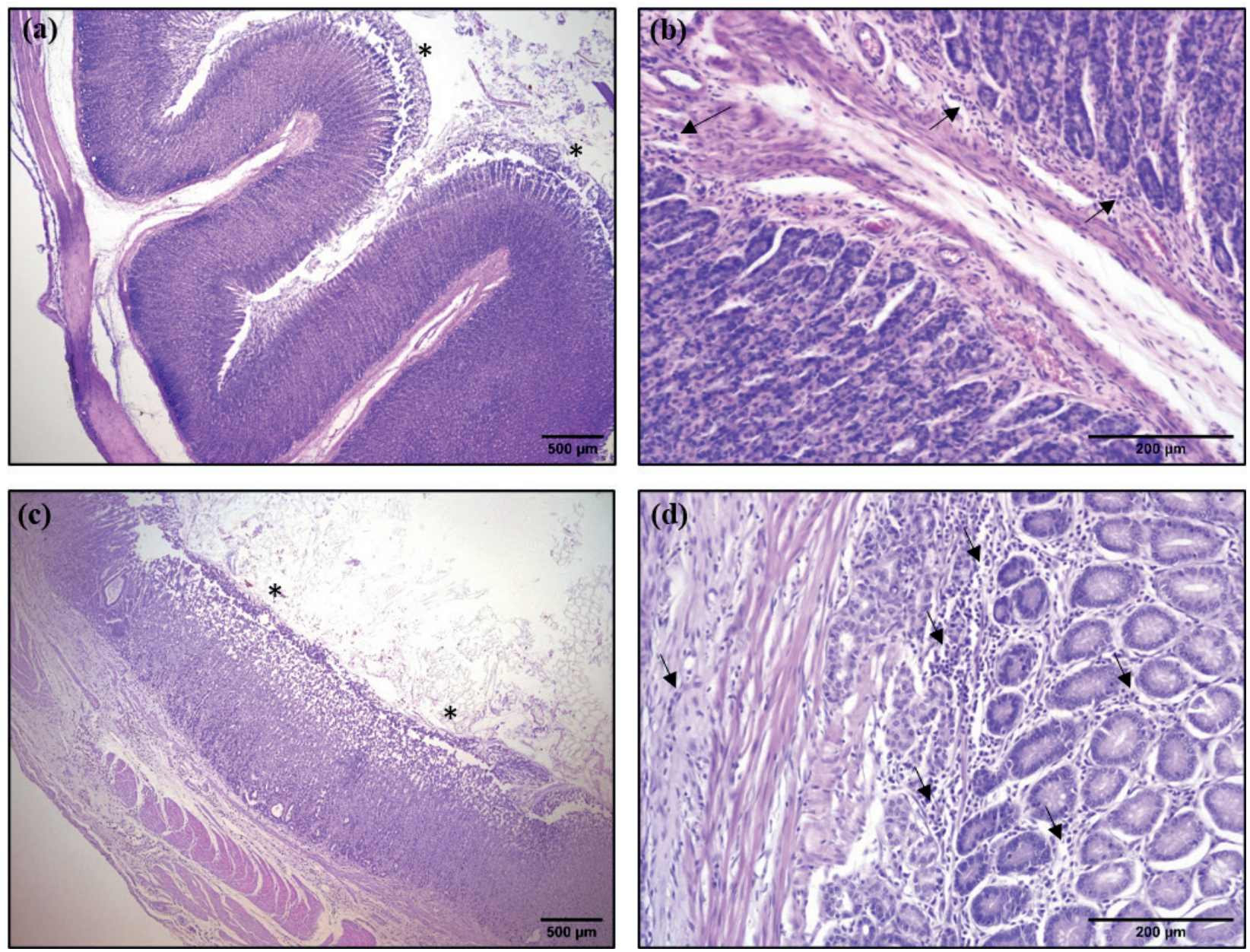

Figure 6. Representative images of 5- $\mu$ m-thick sections of the glandular region of stomachs of of WD-SHAM ( $a$ and b) and WD-VSG (c and d) rats at 3 months after operations; stained with HE. a, shows mild erosion of the mucosa (asterisks) and $b$, reveals mild and diffuse inflammatory infiltrates (arrows) in the mucosa of stomach of WD-SHAM rats. c, shows glandular hypotrophy, intense mucosal erosion (asterisks) and d, demonstrates mild and diffuse inflammatory infiltrate in the mucosa and submucosa (arrows), as well as mucosal edema in the stomachs of WDVSG rats. Scale bars $=200$ or $500 \mu \mathrm{m}$.

\section{DISCUSSION}

Our findings provide new evidence regarding the structural alterations caused in some gastrointestinal organs by the VSG and RYGB surgical procedures. To date, histopathological analyses of the gastrointestinal tract have been performed in the high-fat diet (HFD) obesity model, and in rodents that shifted from a HFD to a normolipidic diet, after bariatric procedures (Martin et al. 2012, Nausheen et al. 2013, Arapis et al. 2015, Mumphrey et al. 2015, Altieri et al.
2015, Cavin et al. 2016). We used the WD model, which uses highly palatable foods that are more similar to those that induce the obesogenic conditions currently observed in Western society, and found gastrointestinal morphological modifications that were dependent on the type of bariatric operation performed. Thus, our findings may resemble those that occur in the digestive organs of subjects submitted to these procedures that do not change their feeding habits, post-surgery. 

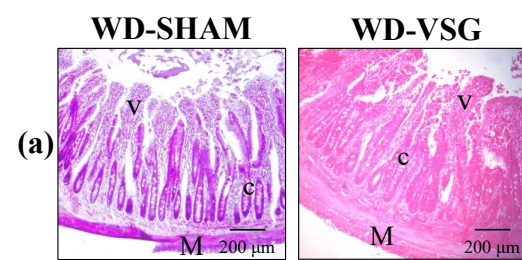

(b)

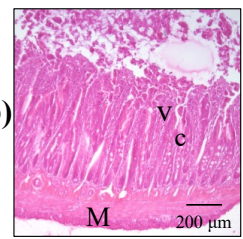

(c)

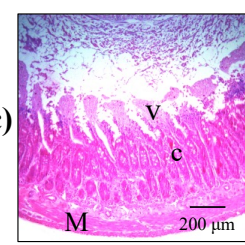

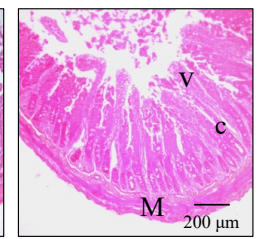

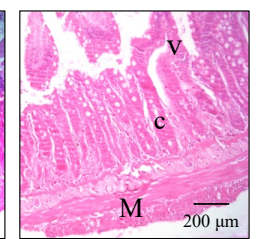

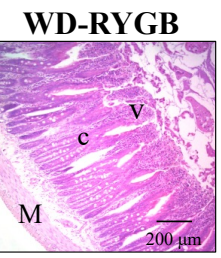
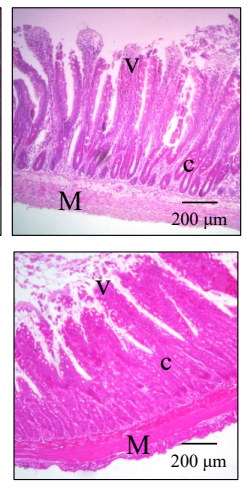

(d)

(e)

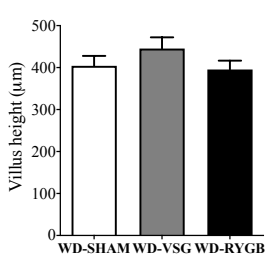

(g)
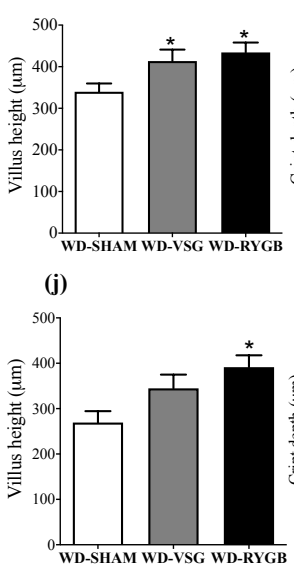

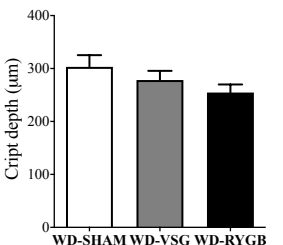

(h)

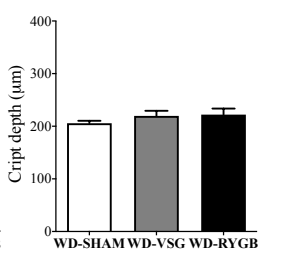

(I)

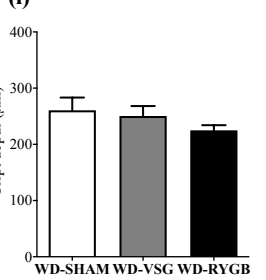

(f)

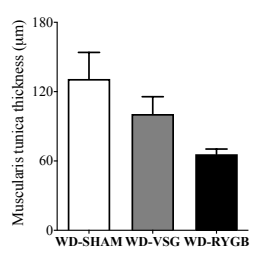

(i)

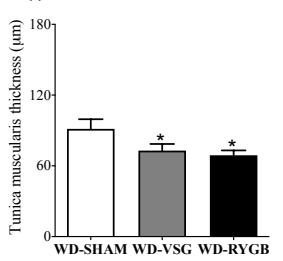

(m)

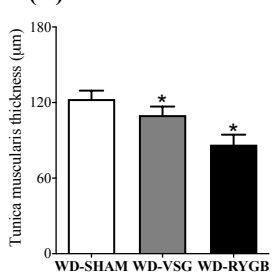

Figure 7. Representative images of 5- $\mu \mathrm{m}$-thick sections of the duodenum (a), jejunum (b) and ileum (c) of WDSHAM, WD-VSG and WD-RYGB rats at 3 months after operations. Means \pm SEM of the villi height ( $d, g$ and $j)$, crypt depth (e, $h$ and $l)$ and tunica muscularis thickness $(f, i$ and $m$ ) of the duodenum, jejunum and ileum, respectively, in the small intestine of WD-SHAM $(n=5)$, WD-VSG $(n=5)$ and WD-RYGB $(n=5)$ rats. *different from WD-SHAM (Kruskal-Wallis followed by Dunns, $\mathrm{P}<0.05$ ).

As previously demonstrated by our laboratory (Silva-Morita et al. 2018) after 3 months of bariatric operations, WD-RYGB rats, but not WD-VSG rats, exhibited lower BW and adiposity. In fact, the RYGB procedure was found to be more efficient for BW loss in rats than the VSG procedure (Arapis et al. 2015). A study also reported no differences in BW at 3 months after VSG in rats that continued to be fed on a HFD (Altieri et al. 2015). Furthermore, studies indicate that the reduction in food consumption after VSG, in HFD rats, occurs for up to 1 month after the operation, and thereafter these rodents display a similar food intake to that of SHAMoperated rats (Martin et al. 2012, Altieri et al. 2015, Arapis et al. 2015, Cavin et al. 2016). These observations may also explain the absence of BW gain in the WD-VSG group during the first month after operation and the return to BW progression during the rest of the experimental period.

There has been debate regarding the effects of bariatric operations on esophagus morphophysiology, as some studies indicate that these procedures can induce/increase gastroesophageal reflux, while others have reported that both VSG and RYGB can improve/ reduce this reflux (Perry et al. 2004, Merrouche et al. 2007, Del Genio et al. 2014, Altieri et al. 2015, Braghetto \& Korn 2019). In our study, we observed an enlargement of the lumen and reductions in collagen content in the upper esophagus in WDRYGB rats. Moreover, WD-RYGB rats displayed a thicker muscularis tunica in this region. It is possible that the reduction in collagen fibers contributed to the dilatation of the upper esophageal lumen in these rats, which may affect upper esophagus motility. Accordingly, at least in RYGB subjects, hypertonia and abnormal 
Table I. Sum up of morphological alterations in gastrointestinal organs of WD-SGV or WD-RYGB rats, when compared to WD-SHAM rats.

\begin{tabular}{|c|c|c|}
\hline & WD-SGV & WD-RYGB \\
\hline \multicolumn{3}{|l|}{ Upper esophagus } \\
\hline Keratin layer thickness & ND & $\downarrow$ \\
\hline Epithelium thickness & ND & $\uparrow$ \\
\hline Tunica mucosa thickness & ND & ND \\
\hline $\begin{array}{c}\text { \% PAS positive area in the } \\
\text { mucosa }\end{array}$ & $\downarrow$ & ND \\
\hline $\begin{array}{c}\% \text { Sirus red positive area in } \\
\text { the mucosa }\end{array}$ & $\downarrow$ & $\downarrow$ \\
\hline Tunica muscularis thickness & ND & $\downarrow$ \\
\hline Area of Lumen & ND & $\uparrow$ \\
\hline Area of Wall Circumference & ND & ND \\
\hline \multicolumn{3}{|l|}{ Lower esophagus } \\
\hline Keratin layer thickness & $\uparrow$ & $\uparrow$ \\
\hline Epithelium thickness & ND & $\uparrow$ \\
\hline Tunica mucosa thickness & ND & $\uparrow$ \\
\hline $\begin{array}{c}\% \text { PAS positive area in the } \\
\text { mucosa }\end{array}$ & $\downarrow$ & $\downarrow$ \\
\hline $\begin{array}{c}\% \text { Sirus red positive area in } \\
\text { the mucosa }\end{array}$ & $\downarrow$ & ND \\
\hline Tunica muscularis thickness & ND & $\uparrow$ \\
\hline Area of Lumen & $\uparrow$ & $\uparrow$ \\
\hline Area of Wall Circumference & ND & $\uparrow$ \\
\hline \multicolumn{3}{|l|}{$\begin{array}{c}\text { Non-glandular region of the } \\
\text { stomach }\end{array}$} \\
\hline Keratin layer thickness & ND & NA \\
\hline Epithelium thickness & ND & NA \\
\hline Tunica mucosa thickness & ND & NA \\
\hline $\begin{array}{l}\text { \% PAS positive area in the } \\
\text { mucosa }\end{array}$ & ND & NA \\
\hline $\begin{array}{c}\% \text { Sirus red positive area in } \\
\text { the mucosa }\end{array}$ & $\downarrow$ & NA \\
\hline Tunica muscularis thickness & ND & NA \\
\hline \multicolumn{3}{|l|}{$\begin{array}{c}\text { Glandular region of the } \\
\text { stomach }\end{array}$} \\
\hline Keratin layer thickness & $\downarrow$ & NA \\
\hline Epithelium thickness & ND & NA \\
\hline Tunica mucosa thickness & ND & NA \\
\hline
\end{tabular}

Table I. Continuation

\begin{tabular}{|c|c|c|}
\hline $\begin{array}{c}\text { \% PAS positive area in the } \\
\text { mucosa }\end{array}$ & $\uparrow$ & NA \\
\hline $\begin{array}{c}\text { \% Sirus red positive area in } \\
\text { the mucosa }\end{array}$ & $\uparrow$ & NA \\
\hline $\begin{array}{c}\text { Duodenum } \\
\text { Villi height }\end{array}$ & ND & ND \\
\hline Crypt depth & ND & ND \\
\hline Junica muscularis thickness & ND & ND \\
\hline Villi height & $\uparrow$ & $\uparrow$ \\
\hline Crypt depth & ND & ND \\
\hline Tunica muscularis thickness & $\downarrow$ & $\downarrow$ \\
\hline Ileum & & \\
\hline Villi height & ND & $\uparrow$ \\
\hline Crypt depth & ND & ND \\
\hline Tunica muscularis thickness & $\downarrow$ & $\downarrow$ \\
\hline
\end{tabular}

Not different (ND); Not analyzed (NA); Increase ( $\uparrow)$; decrease $(\downarrow)$, when compared to WD-SHAM group.

relaxation of the upper esophageal sphincter have been reported (Merrouche et al. 2007, Cassao et al. 2013).

There is evidence that the RYGB procedure improves the lower esophagus sphincter contraction (Merrouche et al. 2007, Cassao et al. 2013), while the VSG procedure worsens it, and also damages esophageal motility and emptying (Braghetto \& Korn 2019). Altieri et al. 2015 demonstrated an increase in the incidence of esophagitis in the esophogastric junction of HFD rats submitted to VSG. We observed that the lower esophagus regions of the WD-VSG and WD-RYGB rats also exhibited enlarged lumens, suggesting luminal dilatation. Additionally, these rodents displayed decreased PAS staining in the tunica mucosa, indicating that bariatric procedures might reduce esophageal mucin synthesis and secretion, in turn diminishing mucosal protection against pepsin and acids during eventual gastric reflux. Such an impairment 
in the esophageal mucosal protection occurs in patients with gastroesophageal reflux, contributing to esophagitis (Namiot et al. 1994). Interestingly, WD-VSG and WD-RYGB rats demonstrated thicker keratin layers in the lower esophagus, which may contribute to enhance the mechanical strength and barrier function to the esophageal epithelium of these rodents despite luminal dilatation and reduced mucus content. Furthermore, WD-RYGB rats displayed thickening of the tunica mucosa and muscularis, augmenting the total wall circumference area of the lower esophagus. We hypothesize that the hypertrophy of the muscularis externa, promoted by RYGB, but not by the VSG operation, could contribute to the improvements in the lower esophagus contractility observed in some subjects submitted to RYGB (Merrouche et al. 2007, Cassao et al. 2013).

Consistent with findings in HFD rats submitted to VSG (Martin et al. 2012), we observed that the stomach of WD-VSG rats exhibited signs of gastric lesions in the mucosa with fibrosis and moderate and diffuse inflammatory infiltration. Conversely, the glandular region of the stomach of WD-VSG rats displayed hypotrophy, contrasting with reports in HFD rats submitted to VSG that were continued or not on a HFD after the surgery (Martin et al. 2012, Arapis et al. 2015). Arapis et al. 2015 showed that HFDfed rats submitted to VSG, and subsequently fed on a normolipidic diet, presented gastric mucosa hyperplasia and reductions in the mRNA for gastric hormones. In turn, Martin et al. (Martin et al. 2012) observed that, at 4 and 16 weeks after VSG, rats that continued on a HFD displayed a normal appearance of the gastric glandular region, with exception of areas close to the suture, which exhibited gastric foveolae elongation with hyperplasia and cystic dilatation (Martin et al. 2012). Therefore, it is likely that the maintenance of WD intake after VSG activates different neuroendocrine pathways in the glandular region, causing hypotrophy of this gastric layer in the WD-VSG group. Accordingly, the WD diet has been shown to cause enlargement of the stomach (Planas et al. 1992) and to upregulate parasympathetic nervous action and gastric hormone secretions (Northway et al. 1989).

In ad dition, as seen in rats submitted to RYGB (Hansen et al. 2013), our study demonstrated that both WD-VSG and WD-RYGB rats did not display any changes in duodenum morphology. On the other hand, the RYGB operation, in particular, has been associated with an increase in the cross-sectional area, mucosa hyperplasia and proliferation of enteroendocrine cells in the jejunum and ileum both in humans and in experimental rodents (Spak et al. 2010, Hansen et al. 2013, Mumphrey et al. 2015, Cavin et al. 2016). Similarly, gut adaptive morphological changes, such as augmented villi height and increased thickness of the tunica muscularis, were observed in the WD-RYGB group, which may enhance absorption and bowel transit in WD-RYGB rats. With regard to VSG, data in the literature are conflicting as to whether this procedure causes morphofunctional changes in the small intestine (Nausheen et al. 2013, Mumphrey et al. 2015, Cavin et al. 2016). Our data demonstrated increased villi height in the jejunum of WD-VSG rats; this effect was also observed in the jejunum of VSG rats that consumed a normolipidic diet and was associated to modifications in enteroendocrine cell morphofunction (Nausheen et al. 2013). Furthermore, we suggest that the thickening of the tunica muscularis in the jejunum and ileum of WD-VSG rats may enhance the final digestion, absorption and transit of the nutrients in the small intestine of these rodents. Therefore, are necessary further investigations about the effects of VSG and/or RYGB on enteroendocrine 
cell morphofunction of rats that continue to consume WD after bariatric operation. In addition, functional analyses of the gastrointestinal organs by motility evaluation should be considered in future studies to better related the main morphological alterations promoted by each bariatric procedure on digestive and absorptive function.

In summary, both the VSG and RYGB operations, when performed in WD rats, lead to dilatation of the upper esophagus due to enlargement of the lumen, in part due to a reduction in collagen content. In the lower esophagus, both types of procedures enlarged the luminal area and decreased mucus content in the mucosa tunica, which may reduce the chemical protection of the mucosa against eventual gastroesophageal reflux. In addition, RYGB causes thickening of the tunica mucosa and muscularis, enlarging the wall circumference of the lower esophagus in WD rats; this effect could account, in part, for the improvement in esophageal contractility. The stomachs of WDVSG rats displayed hypotrophy and signs of lesions and fibrosis of the glandular epithelium. Furthermore, WD rats submitted to VSG or RYGB exhibited modifications in the structures of the jejunum and ileum, which may contribute to alterations in gut digestion, absorption and motility. Is important to emphaticize that the morphological modifications in gastrointestinal organs of WD rats submitted to VSG or RYGB, reported here, would mimic which occurs in subjects that underwent these bariatric techniques but which would not change their eating behavior after operation.

\section{Acknowledgments}

We would like to thank Suellen Camila Padilha, a scientific initiation student and BSc student in Biological Sciences, for helping with caring for experimental animals.

\section{REFERENCES}

ALMEIDA FN, ANDRADE ML, MORAES SMF, CHIMIN P, ALMEIDA KN, PERALTA RM \& NATALI MRM. 2014. Obese adult phenotype: Adaptations of small intestine to cafeteria diet and aerobic physicaltraining after weaning. Science \& Sports 29: $20-26$.

ALTIERI MS, SHROYER KR, PRYOR A, PAGNOTTI GM, ETE CHAN M, TALAMINI M \& TELEM DA. 2015. The association between sleeve gastrectomy and histopathologic changes consistent with esophagitis in a rodent model. Surg Obes Relat Dis. 11: 1289-1294.

ANGRISANI L, SANTONICOLA A, IOVINO P, VITIELLO, A, HIGA K, HIMPENS J, BUCHWALD H \& SCOPINARO N. 2018. IFSO Worldwide Survey 2016: Primary, Endoluminal, and Revisional Procedures. Obes Surg 28: 3783-3794.

ARAPIS K ET AL. 2015. Remodeling of the residual gastric mucosa after roux-en-y gastric bypass or vertical sleeve gastrectomy in diet-induced obese rats. PLOS ONE 10(3): e0121414. doi:10.1371/journal.pone.0121414.

AUNE D, SEN A, PRASAD M, NORAT T, JANSZKY I, TONSTAD S, ROMUNDSTAD P \& VATTEN LJ. 2016. BMI and all cause mortality: systematic review and non-linear doseresponse meta-analysis of 230 cohort studies with 3.74 million deaths among 30.3 million participants. BMJ 353 : i2156353.

BALBO SL, RIBEIRO RA, MENDES MC, LUBACZEUSKI C, MALLER AC, CARNEIRO EM \& BONFLEUR ML. 2016. Vagotomy diminishes obesity in cafeteria rats by decreasing cholinergic potentiation of insulin release. J Physiol Biochem 72: 625-633.

BECERRIL A, CASTILLO-ROBLES G, GONZALEZ-HERNANDEZ M \& VILLANUEVA I. 2005. Influence of high-calorie (cafeteria) diets on the population of Paneth cells in the small intestine of the rat. Eur J Morphol 42(4-5): 201-207. doi:10.1080/09243860600707447.

BHASKARAN K, DOS-SANTOS-SILVA I, LEON DA, DOUGLAS IJ \& SMEETH L. 2018. Association of BMI with overall and causespecific mortality: a population-based cohort study of 3.6 million adults in the UK. Lancet Diabetes Endocrinol 6(12): 944-953. doi:10.1016/S2213-8587(18)30288-2.

BRAGHETTO I \& KORN O. 2019. Late esophagogastric anatomic and functional changes after sleeve gastrectomy and its clinical consequences with regards to gastroesophageal reflux disease. Dis Esophagus 32(6). doi:10.1093/dote/doz020.

CASSAO BD, HERBELLA FA, SILVA LC \& VICENTINE FP. 2013. Esophageal motility after gastric bypass in Roux-en-Y 
for morbid obesity: high resolution manometry findings. Arq Bras Cir Dig 26(Suppl 1): 22-25. doi:10.1590/ s0102-67202013000600006.

CAVIN JB ET AL. 2016. Differences in Alimentary Glucose Absorption and Intestinal Disposal of Blood Glucose After Roux-en-Y Gastric Bypass vs Sleeve Gastrectomy. Gastroenterol 150(2): 454-464 e459. doi:10.1053/j. gastro.2015.10.009.

CHOOI YC, DING C \& MAGKOS F. 2019. The epidemiology of obesity. Metabolism 92: 6-10. doi:10.1016/j. metabol.2018.09.005.

DAMETO MC, RAYO JM, ESTEBAN S, PLANAS B \& TUR JA. 1991. Effect of cafeteria diet on the gastrointestinal transit and emptying in the rat. Comp Biochem Physiol A Physiol 99(4): 651-655. doi:10.1016/0300-9629(91)90145-3.

DEL BAS JM, GUIRRO M, BOQUE N, CERETO A, RAS R, CRESCENTI A, CAIMARI A, CANELA N \& AROLA L. 2018. Alterations in gut microbiota associated with a cafeteria diet and the physiological consequences in the host. Int J Obes 42(4): 746-754. doi:10.1038/ijo.2017.284.

DEL GENIO G ET AL. 2014. Sleeve gastrectomy and development of "de novo" gastroesophageal reflux. Obes Surg 24(1): 71-77. doi:10.1007/s11695-013-1046-4.

FAYFMAN M, FLINT K \& SRINIVASAN S. 2019. Obesity, Motility, Diet, and Intestinal Microbiota-Connecting the Dots. Curr Gastroenterol Rep 21(4): 15. doi:10.1007/ s11894-019-0680-y.

FEAKINS RM. 2016. Obesity and metabolic syndrome: pathological effects on the gastrointestinal tract. Histopathology 68(5): 630-640. doi:10.1111/his.12907.

HANSEN CF, BUETER M, THEIS N, LUTZ T, PAULSEN S, DALBOGE LS, VRANG N \& JELSING J. 2013. Hypertrophy dependent doubling of L-cells in Roux-en-Y gastric bypass operated rats. PLOS ONE 8(6): e65696. doi:10.1371/journal. pone.0065696.

MARTIN M ET AL. 2012. Short- and long-term changes in gastric morphology and histopathology following sleeve gastrectomy in diet-induced obese rats. Obes Surg 22(4): 634-640. doi:10.1007/s11695-012-0606-3.

MERROUCHE M, SABATE JM, JOUET P, HARNOIS F, SCARINGI S, COFFIN B \& MSIKA S. 2007. Gastro-esophageal reflux and esophageal motility disorders in morbidly obese patients before and after bariatric surgery. Obes Surg 17(7): 894-900. doi:10.1007/s11695-007-9166-3.

MUMPHREY MB, HAO Z, TOWNSEND RL, PATTERSON LM\& BERTHOUD HR. 2015. Sleeve Gastrectomy Does Not Cause Hypertrophy and Reprogramming of Intestinal
Glucose Metabolism in Rats. Obes Surg 25(8): 1468-1473. doi:10.1007/s11695-014-1547-9.

NAMIOT Z, SAROSIEK J, MARCINKIEWICZ M, EDMUNDS MC \& MCCALLUM RW. 1994. Declined human esophageal mucin secretion in patients with severe reflux esophagitis. Dig Dis Sci 39(12): 2523-2529. doi:10.1007/bf02087685.

NAUSHEEN S, SHAH IH, PEZESHKI A, SIGALET DL \& CHELIKANI PK. 2013. Effects of sleeve gastrectomy and ileal transposition, alone and in combination, on food intake, body weight, gut hormones, and glucose metabolism in rats. Am J Physiol Endocrinol Metab 305(4): E507-518. doi:10.1152/ajpendo.00130.2013.

NORTHWAY MG, MORRIS M, GEISINGER KR \& MACLEAN DB. 1989. Effects of a gastric implant on body weight and gastrointestinal hormones in cafeteria diet obese rats. Physiol Behav 45(2): 331-335. doi:10.1016/0031-9384(89)90135-2.

NYBERG ST ET AL. 2018. Obesity and loss of disease-free years owing to major non-communicable diseases: a multicohort study. Lancet Public Health 3(10): e490-e497. doi:10.1016/S2468-2667(18)30139-7.

PERRY Y, COURCOULAS AP, FERNANDO HC, BUENAVENTURA PO, MCCAUGHAN JS \& LUKETICH JD. 2004. Laparoscopic Rouxen-Y gastric bypass for recalcitrant gastroesophageal reflux disease in morbidly obese patients. JSLS 8(1): $19-23$.

PLANAS B, PONS S, NICOLAU MC, LOPEZ-GARCIA JÁ \& RIAL R. 1992. Morphofunctional changes in gastrointestinal tract of rats due to cafeteria diet. Rev Esp Fisiol 48(1): 37-43.

PUCCI A \& BATTERHAM RL. 2019. Mechanisms underlying the weight loss effects of RYGB and SG: similar, yet different. J Endocrinol Invest 42(2): 117-128. doi:10.1007/ s40618-018-0892-2.

SILVA-MORITA FS, RIBEIRO RA, BALBO SL, ALEGRE-MALLER ACP, BOSCHERO AC, ARAÚJO ACF \& BONFLEUR ML. 2018. Roux-en-Y gastric bypass is more effective than sleeve gastrectomy against hepatic steatosis, in western-diet-obese rats. Inte J Develop Res 08(07): 21615-21621.

SPAK E, BJORKLUND P, HELANDER HF, VIETH M, OLBERS T, CASSELBRANT A, LONROTH H \& FANDRIKS L. 2010. Changes in the mucosa of the Roux-limb after gastric bypass surgery. Histopathology 57(5): 680-688. doi:10.1111/j.1365-2559.2010.03677.x. 


\section{How to cite}

GUIMARÃES AGC, LOPES LES, CAPELASSI AN, ARAÚJO ACF, BALBO SL, BLANC HNH, FREITAS IN, SILVA JN, RIBEIRO RA \& A BONFLEUR ML. 2021. Morphological alterations in gastrointestinal organs of western-diet obese rats submitted to vertical sleeve gastrectomy or Roux-en-Y gastric bypass. An Acad Bras Cienc 93: 20200884. DOI 10.1590/00013765202120200884.

Manuscript received on June 7, 2020;

accepted for publication on September 11, 2020

\section{ALANA G.C. GUIMARÃES ${ }^{1}$}

https://orcid.org/0000-0002-4111-7489

LUANA E.S. LOPES ${ }^{2}$

https://orcid.org/0000-0002-8661-7065

ANGÉLICA N. CAPELASSI $\left.\right|^{2}$

https://orcid.org/ 0000-0001-8477-8247

ALLAN C.F. ARAÚJO 3

https://orcid.org/0000-0002-6011-8188

SANDRA L. BALBO ${ }^{2}$

https://orcid.org/0000-0002-2866-3928

\section{HELENE N.H. BLANC}

https://orcid.org/ 0000-0001-5729-9785

\section{ISRAELLE N. FREITAS ${ }^{1}$}

https://orcid.org/0000-0002-5360-4268

JULIANA N. SILVA 1

https://orcid.org/0000-0002-9401-3907

ROSANE A. RIBEIRO 4

https://orcid.org/0000-0003-0839-8124

MARIA LÚCIA BONFLEUR ${ }^{2}$

https://orcid.org/0000-0001-5526-7421
'Universidade Federal do Rio de Janeiro, Campus UFRJMacaé, Laboratório de Fisiopatologia, Divisão de Pesquisa Integrada em Produtos Bioativos e Biociências (DPBio), Polo Novo Cavaleiros, Rua Aluízio da Silva Gomes, 50, Granja dos Cavaleiros, 27933-378 Macaé, RJ, Brazil 2Universidade Estadual do Oeste do Paraná (UNIOESTE), Centro de Ciências Biológicas e da Saúde, Laboratório de Fisiologia Endócrina e Metabolismo (LAFEM), Rua Universitária, 1069, 85819-110 Cascavel, PR, Brazil

${ }^{3}$ Universidade Estadual do Oeste do Paraná (UNIOESTE), Centro de Ciências Médicas e Farmacêuticas, Laboratório de Fisiologia Endócrina e Metabolismo (LAFEM), Rua Universitária, 1069, 85819-110 Cascavel, PR, Brazil

${ }^{4}$ Universidade Estadual de Ponta Grossa (UEPG), Setor de Ciências Biológicas e da Saúde (SEBISA), Departamento de Biologia Geral, Campos Uvaranas, Avenida General Carlos Cavalcanti, 4748, 84010-330 Ponta Grossa, PR, Brazil

Correspondence to: Maria Lúcia Bonfleur

E-mail:mlbonfleur@hotmail.com,maria.bonfleur@unioeste.br

\section{Author contributions}

ML Bonfleur and RA Ribeiro: designed the study; AGC Guimarães, LES Lopes, AN Capelassi, HNH Blanc, IN Freitas, JN Silva and RA Ribeiro: executed the research; SL Balbo and ACF Araújo: perfomed bariatric operations; ML Bonfleur and RA Ribeiro: wrote the paper.

\section{(cc) BY}

